\title{
Profil Pendidikan Jasmani Olahraga dan Kesehatan di SMP Negeri se-Kecamatan Buleleng
}

\author{
I Gusti Lanang Agung Pratama Wiguna1* ${ }^{*}$ I Nyoman Kanca², Ni Luh Putu \\ Spyanawati ${ }^{3}$ \\ 1,2,3 Jurusan Pendidikan Olahraga, Universitas Pendidikan Ganesha Singaraja, Indonesia
}

\section{ART ICLE INFO}

\section{Article history:}

Received June 04, 2020

Revised June 07, 2021

Accepted July 17, 2021

Available online July 25, 2021

Kata Kunci:

Profil, PJOK, SMP Negeri

Keywords:

Profile, PJOK, Junior High School

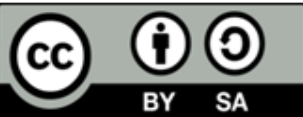

This is an open access article under the CC BY-SA license.

Copyright $(2021$ by Author. Published by Universitas Pendidikan Ganesha.

\begin{abstract}
A B S T R A K
Keberhasilan peserta didik dalam mengikuti proses pembelajaran dipengaruhi oleh dua faktor yaitu faktor internal dan eksternal. Di dalam pembelajaran PJOK, faktor internal memiliki peran yang penting dalam keberhasilan proses pembelajaran, karena faktor internal itu berasal dari dalam diri peserta didik. Faktor eksternal juga memberikan dampak yang sangat besar untuk dapat membantu tercapainya keberhasilan proses pembelajaran. Penelitian ini bertujuan untuk memperoleh data empirik tentang profil pendidikan jasmani olahraga dan kesehatan. Penelitian ini menggunakan pendekatan deskriptif kuantitatif dengan teknik survei. Subjek penelitian ini adalah seluruh SMP Negeri yang berada di Kecamatan Buleleng yang berjumlah 8 Sekolah. Teknik pengumpulan data yang digunakan dalam penelitian ini adalah observasi langsung dalam bentuk wawancara dan kuesioner. Instrumen yang digunakan dalam penelitian ini berpedoman pada PDPJOI. Data yang terkumpul kemudian di analisis dengan analisis deskriptif. Berdasarkan hasil analisis menunjukkan bahwa profil pendidikan jasmani olahraga dan kesehatan berada pada kategori cukup. Implikasi penelitian ini agar profil pendidikan PJOK lebih ditingkatkan lagi.
\end{abstract}

ABS TRAK

The success of students in participating in the learning process is influenced by two factors, namely internal and external factors. In PJOK learning, internal factors have an important role in the success of the learning process, because the internal factors come from within the students. External factors also have a very large impact to be able to help achieve the success of the learning process. This study aims to obtain empirical data about the profile of physical education, sports and health. This study uses a quantitative descriptive approach with survey techniques. The subjects of this study were all junior high schools in Buleleng District, totaling 8 schools. The data collection technique used in this study was direct observation in the form of interviews and questionnaires. The instrument used in this study is guided by the PDPJOI. The collected data is then analyzed by descriptive analysis. Based on the results of the analysis showed that the profile of physical education, sports and health was in the sufficient category. The implication of this research is that the education profile of PJOK is further improved.

\section{PENDAHULUAN}

Proses pembelajaran merupakan inti dari kegiatan pendidikan di sekolah khususnya dalam pembelajaran Pendidikan Jasmani Olahraga dan Kesehatan (PJOK). Pendidikan jasmani merupakan bagian yang tidak terpisahkan dari pendidikan nasional yang bertujuan untuk pengembangkan kemampuan peserta didik melalui aktivitas jasmani (Darmiyanti, Astra, \& Satyawan, 2020). Pendidikan jasmani membentuk kebugaran jasmani, sikap dan karakter dari peserta didik (Pamungkas \& Hariyoko, 2018). Pendidikan Jasmani, Olahraga dan Kesehatan, bertujuan untuk mengembangkan aspek kebugaran jasmani, keterampilan gerak, keterampilan berfikir kritis, keterampilan sosial, penalaran, stabilitas emosional, tindakan moral, aspek pola hidup sehat, dan pengenalan lingkungan bersih melalui aktivitas PJOK (Haris, 2018; Pambudi, Winarno, \& Dwiyogo, 2019; Putra, Artanayasa, \& Suwiwa, 2020). Pendidikan 
jasmani bukan hanya ditujukan untuk mengembangkan kemampuan psikomotorik, akan tetapi juga mengembangkan kemampuan kognitif dan afektif peserta didik (Bramantha, 2017; Hanief \& Sugito, 2015; Paramitha \& Tantra, 2018). Dari beberapa pendapat di atas dapat disimpulkan bahwa pendidikan jasmani adalah pendidikan yang bertujuan mengembangkan kemampuan afektif, kognitif dan psikomotor pada diri peserta didik melalui aktivitas jasmani, olahraga dan kesehatan terpilih yang direncanakan secara sistematis dalam rangka mencapai tujuan pendidikan nasional.

Keberhasilan pelaksanaan pembelajaran PJOK dapat diukur dari keberhasilan peserta didik yang mengikuti pembelajaran tersebut. Keberhasilan dapat dilihat dari tingkat pemahaman, penguasaan materi dan hasil belajar peserta didik. Keberhasilan peserta didik dalam mengikuti proses pembelajaran dipengaruhi oleh dua faktor yaitu faktor internal dan eksternal. Didalam pembelajaran PJOK, faktor internal memiliki peran yang sangat penting dalam menentukan keberhasilan proses pembelajaran karena faktor internal itu berasal dari dalam diri peserta didik. Faktor eksternal juga dapat memberikan dampak yang sangat besar untuk dapat membantu tercapainya keberhasilan proses pembelajaran, dalam hal ini yang dikatakan sebagai bagian dari faktor eksternal meliputi sarana dan prasarana PJOK, tenaga pengajar PJOK, dan Perangkat pembelajaran PJOK itu sendiri. Peran guru dalam proses pembelajaran sangatlah penting untuk menciptakan suasana yang kondusif (Putra et al., 2020). Guru yang baik dan sarana prasarana yang mencukupi, sangat membantu dalam proses pembelajaran pendidikan jasmani sehingga peserta didik menjadi lebih maksimal dalam menerima materi pembelajaran. Peserta didik lebih sering dalam melakukan berbagai keterampilan dan aktivitas di dalam proses pembelajaran sehingga tujuan pembelajaran pendidikan jasmani tercapai dengan baik. Selain itu pada proses pembelajaran pendidikan jasmani, siswa akan sangat dipengaruhi oleh situasi sosial yang dinamis, sehingga peran sosial terhadap pembelajaran sangatlah mempengaruhi perilaku individu untuk menerima materi pembelajaran (Stephani, 2017). Dalam pembelajaran PJOK diperlukan sistematika pembelajaran agar pembelajaran PJOK dapat berjalan dengan baik. Guru PJOK dalam pelaksanaan pembelajaran diharapkan memahami dan menerapkan sistemastika pembelajaran sehingga dapat mendukung keberhasilan tujuan pembelajaran.

Namun berdasarkan hasil observasi awal yang penulis lakukan di SMP Negeri 1 Singaraja, dan SMP Negeri 6 Singaraja, penulis menemukan beberapa kekurangan ketersediaan sarana dan prasarana penunjang pembelajaran PJOK yang berimbas pada kurangnya kesempatan bergerak bagi peserta didik selama proses pembelajaran berlangsung. Hal yang sama juga diungkapkan oleh (Ashfahany, Adi, \& Hariyanto, 2017) yang menunjukkan peserta didik kesulitan dalam belajar, ini dikarenakan sumber belajar yang dapat dipelajari hanya sebatas media cetak yaitu buku yang isi materinya tidak lengkap. Dalam proses pembelajaran PJOK, sangat dibutuhkan model pembelajaran dan media pembelajaran yang tepat untuk menyampaikan materi yang diberikan agar peserta didik dapat memahami dan dapat mengembangkan kemampuan yang sudah dimiliki. Kurangnya media pembelajaran mengakibatkan motivasi siswa dalam mengikuti pembelajaran PJOK masih rendah. Proses pembelajaran yang diberikan guru cenderung monoton. Sehingga dalam proses pembelajaran PJOK sangat dibutuhkan guru yang memang belajar dan ahli di bidangnya yaitu guru pelajaran PJOK bukan guru kelas yang merangkap sebagai guru mapel. Namun berdasarkan hasil observasi banyak sekolah yang belum memiliki ketersediaan guru, sarana dan prasarana yang memadai untuk menunjang proses pembelajaran PJOK. Kurangnya sarana dan prasarana dalam belajar akan berdampak terhadap minat dan hasil belajar siswa. (Wijaya, 2017)

Maka dengan kecendrungan berdasarkan hasil observasi awal untuk mencapai tujuan pendidikan nasional khususnya PJOK tersebut, pemerintah baik pemerintah pusat maupun pemerintah daerah perlu menyiapkan konsep kebijakan strategis di bidang PJOK. Upaya menyusun konsep kebijakan strategis tersebut memerlukan data lapangan yang cukup memadai, sehingga kebijakan yang disusun akan sesuai dengan kebutuhan disekolah dan kebutuhan pembangunan nasional. Tanpa memiliki data yang faktual, pembangunan hanya akan berlandaskan pada isu-isu permasalahan yang berkembang di masyarakat pada saat ini, yang dapat menyesatkan kebijakan pembangunan keolahragaan (Lanang \& Parwata, 2018). Langkah yang dilakukan untuk membangun keolahragaan yang kokoh, memerlukan analisis dan peluang pengembangannya untuk kurun waktu berikutnya. Untuk itu diperlukan data tentang pengembangan PJOK dalam bentuk profil pendidikan jasmani olahraga dan kesehatan. Penelitian ini didukung dengan beberapa penelitain yang dianggap relevan dengan variable penelitian ini, seperti : Penelitian oleh (Sulaksana, Kanca., \& Wijaya, 2020) yang mengemukakan bahwa Sarana dan prasarana PJOK SMA dan SMK se-Kecamatan Gerokgak termasuk kategori cukup oleh karena itu pihak terkait agar senantiasa memperhatikan ketersediaan guru dan sarana prasarana demi kelancaran suatu pembelajaran secara maksimal 2) Penelitian oleh (Cahya Pratama, 2018) yang mengemukakan mengenai Survei Sarana Prasarana Pendidikan Jasmani Olahraga Dan Kesehatan, Sekolah Menengah Pertama Dan Sederajat yang menunjukkan hasil bahwa ketersediaan sarana dan prasarana pembelajaran PJOK pada jenjang sekolah 
menengah pertama berada dalam kategori cukup, hal ini menandakan bahwa ketersediaan sarana dan prasarana masih perlu ditingkatkan. 3) Penelitian oleh (Lestari, Parwata, \& Dartini, 2020) menunjukkan bahwa sarana dan prasarana di SMP se-kecamatan Pupuan masih banyak sarana dan prasarana yang kurang memadai, baik dari segi bentuk, kondisi, dan status kepemilikannya. Penelitian mengenai profil PJOK yaitu tentang sarana sarana dan prasarana pembelajaran pendidikan jasmani telah diteliti di berbagai tempat dengan hasil yang bervariasi. Adapun hal yang membedakan antara penelitian ini dengan penelitian sebelumnya yakni penelitian ini sarana dan prasarana pembelajaran PJOK pada pada jenjang sekolah menengah pertama. Tujuan dari penelitian ini adalah sebagai berikut: Untuk mengetahui profil PJOK yaitu tentang ketersediaan guru, ketersediaan perangkat pembelajaran serta ketersediaan prasarana dan sarana PJOK SMP Negeri Se-Kecamatan Buleleng tahun 2021.

Lembaga penyelenggara pendidikan formal harus menyertakan PJOK, serta mengadakan segala sesuatu yang dibutuhkan agar proses pembelajaran dapat terselenggara dengan baik dan berkualitas. Agar proses pembelajaran dapat terlaksana dengan baik dan berkualitas, perlu didukung dengan ketersediaan sarana dan prasarana yang memadai. Namun dalam pelaksanaannya sarana dan prasarana yang tersedia di sekolah masih belum di manfaatkan dengan maksimal. Proses Pembelajaran PJOK juga idealnya dilakukan secara teratur dalam silabus yang sesuai dengan standar sekolah yang sudah ditentukan oleh Departemen Pendidikan Nasional. PJOK merupakan bagian yang tidak terpisahkan dari pendidikan secara keseluruhan. PJOK memiliki kedudukan yang khas dalam pendidikan karena PJOK mengembangkan ranah psikomotor sebagai tujuan utamanya, tetapi tidak mengabaikan pengembangan ranah kognitif dan afektif. PJOK juga mempunyai peran yang unik dibandingkan dengan mata pelajaran yang lain, karena PJOK dapat digunakan untuk pengembangan aspek fisik dan pesikomotor, dan juga ikut berperan dalam pengembangan aspek kognitif dan afektif secara serasi dan seimbang di dalam kehidupan sehari - hari.

\section{METODE}

Jenis penelitian ini adalah penelitian deskriptif, yaitu suatu penelitian yang bertujuan untuk mengetahui dan mendapatkan gambaran atau kenyataan yang sesungguhnya dari keadaan objek yang diteliti. Tujuan penelitian ini adalah untk mengetahui profil sekolah yang mencangkup ketersedian guru, ketersediaan perangkat pembelajaran dan ketersediaan saran dan prasarana belajar di SMP Negeri se Kecamatan Buleleng. Metode yang digunakan adalah survei dengan teknik pengumpulan data menggunakan instrumen penelitian. Dalam penelitian ini variabel yang digunakana adalah profil pendidikan jasmani olahraga dan kesehatan di SMP Negeri se-Kecamatan Buleleng. Subjek dalam penelitian ini adalah seluruh SMP Negeri yang berada di Kecamatan Buleleng. Dengan Jumlah satuan pendidikan SMP Negeri se-Kecamatan Buleleng yang di teliti sebanyak 8 Sekolah.

Instrumen yang digunakan dalam penelitian ini berpedoman pada PDPJOI. PDPJOI ini merupakan gagasan Asisten Deputi Olahraga Pendidikan atau (Asdep Ordik). Deputi Pemberdayaan Olahraga, Kementrian Pemuda dan Olahraga Republik Indonesia, yang kegiatannya sudah dilaksanakan mulai tahun 2006. Data dasar yang dihimpun dari masing-masing satuan pendidikan meliputi 3 aspek, yaitu:1) kondisi riil sarana dan prasarana PJOK, 2) kondisi riil ketersediaan guru PJOK dan 3) ketersediaan perangkat pemblajaran PJOK. Teknik pengumpulan data yang digunakan dalam penelitian ini adalah observasi langsung dalam bentuk Wawancara dan kuesioner yang di isi oleh guru-guru PJOK SMP Negeri seKecamatan Buleleng. Setelah data terkumpul akan dianalis menggunakan analisis deskriptif. Analisis deskriptif bersifat menggambarkan hasil penelitian yang dilakukan. Dalam penelitian ini akan digambarkan mengenai kondisi riil sarana dan prasarana PJOK, kondisi riil tenaga pengajar PJOK dan ketersediaan perangkat pemblajaran PJOK di SMP Negeri Se-Kecamatan Buleleng.Dalam PDPJOI 2007:27, terdapat pedoman yang menjelaskan bahwa terdapat 5 tingkat kategori A, B, C, D, dan E. 5 kategori inilah yang dipakai sebagai ukuran kemajuan pelaksanaan PJOK di masing-masing Sekolah adapun 5 kategori tersebut yaitu.

Tabel 1. Kategori penilaian

\begin{tabular}{ccl}
\hline Nilai & Kategori & \\
\hline 700 keatas & A & Keterangan \\
$525-699$ & B & Baik \\
$350-524$ & C & Cukup \\
$175-345$ & D & Kurang \\
$0-174$ & E & Kurang Sekali \\
\hline
\end{tabular}




\section{HASIL DAN PEMBAHASAN}

Setelah peneliti melakukan penelitian profil pendidikan jasmani olahraga dan kesehatan di SMP Negeri se-Kecamatan Buleleng, yang dilakukan dengan mengisi instrument yang berisi 3 aspek yaitu: 1) kondisi riil sarana dan prasarana PJOK, 2) kondisi riil ketersediaan tenaga pengajar PJOK dan 3) ketersediaan perangkat pembelajaran PJOK. Selanjutnya data yang didapat akan di masukkan ke dalam format penilaian instrumen PDPJOI. Data ketersedian guru PJOK dapatd dilihat pada Tabel 2 berikut. Berdasarkan Tabel 2 dapat di lihat dari nilai rata-rata di atas untuk setiap data yang diteliti dapat digolongkan atau di kategorikan sebagai berikut: untuk ketersediaan guru PJOK di 8 sekolah SMP Negeri yang diteliti mendapat nilai rata-rata 137 dan dikategorikan "C" atau Cukup, dari pernyataan tersebut dapat dijelaskan bahwa ketersediaan guru PJOK di seluruh SMP Negeri yang ada di Kecamatan buleleng sudah cukup memadai dan masih perlu di tingkatkan lagi karna kualitas dan kuantitas guru PJOK sangat berpengaruh terhadap kualitas pembelajaran PJOK di sekolah. Untuk data ketersediaam perangkat pembelajaran dapat dilihatpada Tabel 3.

Tabel 2. Ketersediaan guru PJOK

\begin{tabular}{cccc}
\hline No & Nama sekolah & Nilai & Kategori \\
\hline 1 & SMP NEGERI 1 SINGARAJA & 130 & $\mathrm{C}$ \\
2 & SMP NEGERI 2 SINGARAJA & 130 & $\mathrm{C}$ \\
3 & SMP NEGERI 3 SINGARAJA & 170 & $\mathrm{~B}$ \\
4 & SMP NEGERI 4 SINGARAJA & 140 & $\mathrm{C}$ \\
5 & SMP NEGERI 5 SINGARAJA & 130 & $\mathrm{C}$ \\
6 & SMP NEGERI 6 SINGARAJA & 140 & $\mathrm{C}$ \\
7 & SMP NEGERI 7 SINGARAJA & 170 & $\mathrm{~B}$ \\
8 & SMP NEGERI 8 SINGARAJA & 90 & $\mathrm{D}$ \\
\hline
\end{tabular}

Tabel 3. Ketersediaan Perangkat Pembelajaran

\begin{tabular}{cccc}
\hline No & Nama sekolah & Nilai & Kategori \\
\hline 1 & SMP NEGERI 1 SINGARAJA & 110 & $\mathrm{C}$ \\
2 & SMP NEGERI 2 SINGARAJA & 110 & $\mathrm{C}$ \\
3 & SMP NEGERI 3 SINGARAJA & 110 & $\mathrm{C}$ \\
4 & SMP NEGERI 4 SINGARAJA & 110 & $\mathrm{C}$ \\
5 & SMP NEGERI 5 SINGARAJA & 110 & $\mathrm{C}$ \\
6 & SMP NEGERI 6 SINGARAJA & 110 & $\mathrm{C}$ \\
7 & SMP NEGERI 7 SINGARAJA & 110 & $\mathrm{C}$ \\
8 & SMP NEGERI 8 SINGARAJA & 110 & $\mathrm{C}$ \\
\hline
\end{tabular}

Berdasarkan Tabel 3 menunjukkan bahwa untuk ketersediaan perangkat pembelajaran PJOK di 8 sekolah SMP Negeri yang diteliti mendapat nilai rata-rata 110 dan dikategorikan "C" atau Cukup, dari pernyataan tersebut dapat dijelaskan bahwa ketersediaan perangkat pembelajaran PJOK di seluruh SMP Negeri yang ada di Kecamatan buleleng sudah cukup memadai dan masih perlu di tingkatkan lagi karna hal ini akan berpengaruh terhadap kualitas pembelajaran PJOK di sekolah. Data ketersediaan sarana dan prasarana dapat dilihat pada Tabel 4.

Tabel 4. Ketersediaan Sarana dan Prasarana

\begin{tabular}{cccc}
\hline No & Nama sekolah & Nilai & Kategori \\
\hline 1 & SMP NEGERI 1 SINGARAJA & 149 & $\mathrm{C}$ \\
2 & SMP NEGERI 2 SINGARAJA & 163 & $\mathrm{C}$ \\
3 & SMP NEGERI 3 SINGARAJA & 130 & $\mathrm{C}$ \\
4 & SMP NEGERI 4 SINGARAJA & 94 & $\mathrm{D}$ \\
5 & SMP NEGERI 5 SINGARAJA & 163 & $\mathrm{C}$ \\
6 & SMP NEGERI 6 SINGARAJA & 50 & $\mathrm{E}$ \\
7 & SMP NEGERI 7 SINGARAJA & 48 & $\mathrm{E}$ \\
8 & SMP NEGERI 8 SINGARAJA & 15 & $\mathrm{E}$ \\
\hline
\end{tabular}


Bedasarkan Tabel 4 ketersediaan sarana dan prasarana PJOK di 8 sekolah SMP Negeri yang diteliti mendapat nilai rata-rata 101 dan dikategorikan " $\mathrm{D}$ " atau Kurang, dari pernyataan tersebut dapat dijelaskan bahwa ketersediaan sarana dan prasarana PJOK di seluruh SMP Negeri yang ada di Kecamatan buleleng masih kurang memadai dan sangat perlu di tingkatkan lagi karna hal ini akan berpengaruh terhadap kualitas pembelajaran PJOK di sekolah. Hasil rekapitulasi total skor data profil PJOK dapat dilihat pada Tabel 5 .

Tabel 5. Total Skor Ketersediaan Guru PJOK, Ketersediaan Perangkat Pembelajaran PJOK, Ketersediaan Sarana dan Prasarana PJOK di Masing-Masing Skolah

\begin{tabular}{cccccc}
\hline No & Nama sekolah & $\begin{array}{c}\text { Ketersediaan } \\
\text { Tenaga } \\
\text { pengajar PJOK }\end{array}$ & $\begin{array}{c}\text { Ketersediaan } \\
\text { Perangkat } \\
\text { pemblajaran PJOK }\end{array}$ & $\begin{array}{c}\text { Ketersediaan } \\
\text { Sarana dan } \\
\text { Prasarana PJOK }\end{array}$ & $\begin{array}{c}\text { Total } \\
\text { skor }\end{array}$ \\
\hline 1 & SMP NEGERI 1 SINGARAJA & 130 & 110 & 149 & 389 \\
2 & SMP NEGERI 2 SINGARAJA & 130 & 110 & 163 & 403 \\
3 & SMP NEGERI 3 SINGARAJA & 170 & 110 & 130 & 410 \\
4 & SMP NEGERI 4 SINGARAJA & 140 & 110 & 94 & 344 \\
5 & SMP NEGERI 5 SINGARAJA & 130 & 110 & 163 & 403 \\
6 & SMP NEGERI 6 SINGARAJA & 140 & 110 & 50 & 300 \\
7 & SMP NEGERI 7 SINGARAJA & 170 & 110 & 48 & 328 \\
8 & SMP NEGERI 8 SINGARAJA & 90 & & 15 & 215 \\
\hline
\end{tabular}

Temuan pertama, dalam penelitian ini menunjukkan ketersediaan guru PJOK di 8 sekolah SMP Negeri berada pada kategorikan "C" atau Cukup. Guru adalah tenaga professional yang bertugas merencanakan dan melaksanakan proses pembelajaran, dan menilai pembelajaran (Malyana, 2020). Guru memegang peranan sentral dalam proses belajar mengajar (Hardiyana, 2014). Untuk itu mutu pendidikan di suatu sekolah sangat ditentukan oleh kemampuan yang dimiliki seorang guru dalam menjalankan tugasnya. Guru merupakan orang tua siswa dalam lingkungan sekolah. Maka peran guru begitu berarti dalam membentuk kepribadian peserta didik diluar dari pengaruh lingkungannya (Palunga \& Marzuki, 2017). Guru harus mampu mengembangkan pembelajaran yang efektif, disamping harus memahami dan memperhatikan karakteristik dan kebutuhan siswa (Arifin, 2017). Guru pendidikan jasmani perlu memiliki bekal pengetahuan tentang karakteristik peserta didik dan keterampilan dalam memformulasikan metode atau model pembelajaran yang dapat mendukung tercapainya tujuan dari pendidi kan jasmani itu sendiri (Suherman, 2016). Temuan kedua, ketersediaan perangkat pembelajaran PJOK di 8 sekolah SMP Negeri yang terdapat kategori cukup. Artinya telah dapat membantu proses pembelajaran namun masih perlu untuk ditingkatkan guna mencapai tujuan pembelajaran. Perangkat pembelajaran adalah alat atau perlengkapan untuk melaksanakan proses yang memungkinkan pendidik dan peserta didik melakukan kegiatan pembelajaran (Zuhdan, 2011). Perangkat pembelajaran dibuat sebagai salah satu penunjang agar pembelajaran dapat berjalan dengan baik (Kusumawati \& Sumardi, 2016).

Temuan ketiga, ketersediaan sarana dan prasarana PJOK di 8 sekolah SMP Negeri berada pada kategori D atau Kurang. prasarana pendidikan adalah perlengkapan dasar/fasilitas dasar yang secara tidak langsung menunjang jalannya proses pendidikan atau pengajaran, seperti ruang kelas, ruang laboratorium, ruang perpustakaan, dan ruang atau tempat lain yang diperlukan dalam proses pembelajaran. Ketersediaan guru dan sarana prasarana di Indonesia khususnya di sekolah harus memiliki tenaga pendidik yang professional dan sarana prasarana yang memadai sehingga proses belajar mengajar terlaksana dengan baik. Pembelajaran penjasorkes dapat berlangsung efekif jika sarana dan prasarana yang sesuai dengan materi terpenuhi dan dapat dimanfaatkan secara maksimal untuk pencapaian tujuan pembelajaran. Penelitian ini sejalan dengan penelitain yang dilakukan oleh 1) (Sudibyo \& Nugroho, 2020) yang menunjukkan bahwa keadaan sarana dan prasarana olahraga di 3 SMP kabupaten Pringsewu dalam kategori cukup ideal untuk mendukung pembelajaran. Hal ini disebabkan karena sejumlah guru telah membu berinovasi dan memanfaatkan bahan sederhana menjadi suatu inovasi alat pembelajaran pendidikan jasmani. 2) penelitian oleh (Fraliantina, 2016) mengenai Pengaruh Kepemimpinan Dan Sarana Prasarana Olahraga Terhadap Prestasi Sekolah Di Bidang Olahraga yang menunjukkan hasil bahwa kepemimpinan kepala sekolah dan ketersediaan sarana dan prasarana memberikan pengaruh yang positif terhadap hasil belajar PJOK siswa, sehingga ketersediaan sarana dan prasarana harus mampu memenuhi kebutuhan pembelajaran siswa. 3) Penelitian oleh (Muliadi, 2019) tentang Profil Sarana Dan Prasarana Pengajaran Pendidikan Jasmani yang menunjukkan bahwa keadaan sarana dan prasarana untuk kegiatan pengajaran pendidikan jasmani di Sekolah Dasar Negeri Kec.Tanete Riattang Barat Kab. Bone, masih 
belum memadai sesuai dengan tuntutan kurikulum. Hasil penelitian ini berimplikasi agar guru pendidikan jasmani hendaknya lebih kreatif untuk dapat menanggulangi kekurangan alat-alat dengan memodifikasi alat-alat yang ada, sehingga proses belajar mengajar tetap dapat berlangsung dengan wajar. Bagi pihak sekolah dan pemerintah agar lebih memperhatikan, mengalokasikan dan menganggarkan dana untuk melengkapi perangkat pembelajaran PJOK, sarana dan prasarana pembelajaran PJOK, juga lebih memper hatikan jumlah dan setatus guru PJOK disekolah secara berkelanjutan, agar proses pembelajaran PJOK menjadi lebih efektif dan optimal karena didukung oleh 3 aspek itu sendiri.

\section{SIMPULAN DAN SARAN}

Berdasarkan hasil penelitian dan pembahasan yang sudah dilakukan dapat disimpulkan bahwa profil pendidikan jasmani dan kesehatan yang mencangkup ketersedian guru, ketersedian perangkat pembelajaran serta ketersediaan sarana dan prasarana pembelajaran PJOK di 8 sekolah SMP Negeri seKecamatan Buleleng tahun 2021 berada dalam kategori cukup sehingga dengan adanya penelitian ini dapat di jadikan acuan untuk sekolah maupun pemerintah dalam mengambil langkah selanjutnya, demi keberhasilan proses belajar mengajar di sekolah khususnya dalam pembelajaran PJOK.

\section{DAFTAR RUJUKAN}

Arifin, S. (2017). Internalisasi Nilai Sportivitas Melalui Pembelajaran Pendidikan Jasmani di Sekolah Dasar. Jurnal Sosioreligi, $15(2), \quad 20-29 . \quad$ Retrieved from. https://ejournal.upi.edu/index.php/SosioReligi/article/view/8834.

Ashfahany, F. A., Adi, S., \& Hariyanto, E. (2017). Bahan Ajar Mata Pelajaran Pendidikan Jasmani Olahraga Dan Kesehatan Dalam Bentuk Multimedia Interaktif Untuk Siswa Kelas Vii. Jurnal Pendidikan: Teori, Penelitian, Dan Pengembangan, 2(2), 261 - 267. https://doi.org/10.17977/jp.v2i2.8540.

Bramantha, H. (2017). Pengembangan Bahan Ajar Penjaskes Pokok Bahasan Teknik Dasar Renang Gaya Bebas Dengan Pendekatan Kontekstual Pada Siswa Kelas X Di Smk Daerah Situbondo. Jurnal Pendidikan Dasar Indonesia, 2(2), 25-27. https://doi.org/10.26737/jpdi.v2i2.326.

Cahya Pratama, A. (2018). Survei Sarana Prasarana Pendidikan Jasmani Olahraga Dan Kesehatan, Sekolah Menengah Pertama Dan Sederajat. Jurnal Pendidikan Olahraga Dan Kesehatan, 6(3), 561-564.

Darmiyanti, K. R., Astra, I. K. B., \& Satyawan, I. M. (2020). Pengaruh Model Pembelajaran Kooperatif Tipe Student Teams Achievement Division Terhadap Hasil Belajar Teknik Dasar Sepak Sila Dalam Permainan Sepak Takraw. Jurnal Ilmu Keolahragaan Undiksha, 8(3), 136-145. https://doi.org/10.23887/jiku.v8i3.29826.

Fraliantina, I. A. (2016). Pengaruh Kepemimpinan Dan Sarana Prasarana Olahraga Terhadap Prestasi Sekolah Di Bidang Olahraga. JUARA: Jurnal Olahraga, 1(2), 100. https://doi.org/10.33222/juara.v1i2.24.

H, H., \& Riady, A. (2018). Survey Sarana Dan Prasarana Pendidikan Jasmani Di SMP/ MTS Swasta Kabupaten Pangkep. SPORTIVE: Journal Of Physical Education, Sport and Recreation, 1(2), 27. https://doi.org/10.26858/sportive.v1i2.5624.

Hanief, Y. N., \& Sugito, S. (2015). Membentuk Gerak Dasar Pada Siswa Sekolah Dasar Melalui Permainan Tradisional. Jurnal SPORTIF: Jurnal Penelitian Pembelajaran, 1(1), 100-113. https://doi.org/10.29407/js_unpgri.v1i1.575.

Hardiyana, S. (2014). Pengaruh Guru PKn terhadap Pembentukan Karakter Siswa. Jurnal Ilmiah PPKn IKIP Veteran Semarang., 1(2), 54-64. Retrieved from. https://ejournal.upi.edu/index.php/SosioReligi/article/view/8834.

Haris, I. N. (2018). Model pembelajaran peer teaching dalam pembelajaran pendidikan jasmani. Journal of Chemical Information and Modeling, 4(9), 2.

Kusumawati, A. D., \& Sumardi, Y. (2016). Peranan Perangkat Pembelajaran Fisika Berbasis Elaboration Learning Untuk Siswa Sma. UPEJ Unnes Physics Education Journal, 5(2), 42-53. https://doi.org/10.15294/upej.v5i2.13619.

Lanang, I. G., \& Parwata, A. (2018). Profil Pendidikan Jasmani , Olahraga dan Kesehatan SMA / SMK di Kabupaten Buleleng. Seminar Nasional Riset Inovatif 2018, 415-419. https://doi.org/10.23887/jjp.v8i2.33758.

Lestari, L. K. G. A. D., Parwata, I. G. L. A., \& Dartini, N. P. D. S. (2020). Keterserdiaan Sarana Dan Prasarana Penunjang Pembelajaran Pjok Tingkat Smp Se-Kecamatan Pupuan. Jurnal Pendidikan Jasmani Olahraga Dan Kesehatan, 8(3), 124-132. https://doi.org/10.23887/jjp.v8i3.33767.

Malyana, A. (2020). Pelaksanaan Pembelajaran Daring Dan Luring Dengan Metode Bimbingan Berkelanjutan Pada Guru Sekolah Dasar Di Teluk Betung Utara Bandar Lampung. Pedagogia: 
Jurnal Ilmiah Pendidikan Dasar Indonesia, 2(1), 67-76. https://doi.org/10.52217/pedagogia.v2i1.640.

Muliadi. (2019). Profil Sarana Dan Prasarana Pengajaran Pendidikan Jasmani Di Sekolah Dasar Negeri Kec. Tanete Riattang Barat Kabupaten Bone. JIKAP PGSD: Jurnal IImiah IImu Kependidikan, 3(1), 35-39. https://doi.org/10.26858/jkp.v3i1.8138.

Palunga, R., \& Marzuki. (2017). Peran Guru Dalam Pengembangan Karakter Peserta Didik Di Sekolah Menengah Pertama Negeri 2 Depok Sleman. Jurnal Pendidikan Karakter, 8(1), 109-123. https://doi.org/10.21831/jpk.v7i1.20858.

Pambudi, M. I., Winarno, M., \& Dwiyogo, W. D. (2019). Perencanaan dan Pelaksanaan Pembelajaran Pendidikan Jasmani Olahraga Kesehatan. Jurnal Pendidikan Olahraga, Universitas Negeri Malang, 4(1), 110-116.

Pamungkas, T. S., \& Hariyoko. (2018). Pengaruh Metode Drill Dan Metode Barrier Hops Terhadap Hasil Belajar Shooting. Gelanggang Pendidikan Jasmani Indonesia, 2(1), 46-51. https://doi.org/10.17977/um040v2i1p46-51.

Paramitha, \& Tantra, S. (2018). Revitalisasi Pendidikan Jasmani untuk Anak Usia Dini melalui Penerapan Model Bermain Edukatif Berbasis Alam. Jurnal Pendidikan Jasmani Dan Olahraga, 3(1), 41-51. https://doi.org/10.17509/jpjo.v3i1.10612.

Putra, G. N. K. W., Artanayasa, I. W., \& Suwiwa, I. G. (2020). Pengaruh Modelpembelajaran Kooperatif Tipe Numbered Head Together Berbantuan Media Gambar Terhadap Hasil Belajar Teknik Dasar Passing Bola Voli. Jurnal Ilmu Keolahragaan Undiksha, 8(3), 164-172. https://doi.org/10.23887/jiku.v8i3.29823.

Stephani, M. R. (2017). Stimulasi Kemampuan Berpikir Kritis Melalui Pembelajaran Berbasis Masalah Pada Pendidikan Jasmani. Jurnal Pendidikan Jasmani Dan Olahraga, 2(1), 16-27. https://doi.org/10.17509/jpjo.v2i1.6397.

Sudibyo, N. A., \& Nugroho, R. A. (2020). Survei sarana dan prasarana pembelajaran pendidikan jasmani olahraga dan kesehatan pada sekolah menengah pertama di kabupaten pringsewu tahun 2019. Journal of Physical Education (JouPE), 1(1), 18-24. https://doi.org/10.33365/joupe.v1i1.182.

Suherman, A. (2016). Pengaruh Penerapan Model Kooperatif Tipe Jigsaw Dan Tgt (Teams Game Tour_nament) Terhadap Keterampilan Sosial Dan Ket_erampilan Bermain Bolavoli. JURNAL PENDIDIKAN JASMANI DAN OLAHRAGA, 1(2), 8-15. Retrieved from. http://ejournal.upi.edu/index.php/\%0Apenjas/article/view/2216/3884.

Sulaksana, P. P., Kanca., I. N., \& Wijaya, M. A. (2020). Ketersediaan Guru Dan Sarana Prasarana Pjok Sma Dan Smk Se-Kecamatan Gerokgak Kabupaten Buleleng. Jurnal Pendidikan Jasmani Olahraga Dan Kesehatan, 8(2), 69-74.

Wijaya, F. (2017). Ketersediaan Sarana Dan Prasarana Pembelajaran Pendidikan Jasmani, Olahraga Dan Kesehatan Di Sma Negeri Kabupaten Sumenep. Jurnal Pendidikan Olahraga Dan Kesehatan, 5(2), 232-235.

Zuhdan, P. K. (2011). Pengembangan Perangkat Pembelajaran Sains Terpadu Untuk Meningkatkan Kognitif, Keterampilan Proses, Kreativitas serta Menerapkan Konsep Ilmiah Peserta Didik SMP. Program Pascasarjana UNY. 